\title{
A Construção da Identidade de Jovens e Adolescentes de uma Escola da Região Metropolitana do Rio Grande do Sul a partir das Selfies
}

\author{
La Construcción de la Identidad de Jóvenes y Adolescentes de una Escuela \\ de la Región Metropolitana de Rio Grande do Sul a partir de las Selfies \\ The Construction of the Identity of Young People and Adolescents of a \\ School in the Metropolitan Region of Rio Grande do Sul from the Selfies
}

Daiane Fontes ${ }^{1}$

Jaqueline da Silva Torres Cardoso ${ }^{2}$

Sandra Maria Costa dos Passos Colling ${ }^{3}$

\begin{abstract}
Resumo
A popularização das tecnologias digitais alterou o modo de como as relações sociais são estabelecidas na contemporaneidade. $\mathrm{O}$ ato de fotografar-se ganhou novos significados. Partindo dessa perspectiva, o presente artigo tem como objetivos analisar as narrativas construídas por jovens estudantes a partir das selfies, além de compreender os significados construídos por eles em torno dessas imagens. As técnicas de pesquisa utilizadas foram as entrevistas de grupo focal e entrevistas individuais com a professora e com os estudantes do Atendimento Educacional Especializado da Escola Municipal de Ensino Fundamental Gonçalves Dias, localizada na cidade de Portão (RS). O interesse pela pesquisa surgiu a partir de um projeto apresentado pelos estudantes na FEICIP, Feira de Iniciação Científica do referido município intitulado: "Selfie não é só curtir: um estudo na E.M.E.F. Gonçalves Dias". Como embasamento teórico, recorreu-se aos conceitos de construção de narrativas (RICOEUR, 2012) a partir do imaginário (PESAVENTO, 1995) produzido pelas selfies (SIBILIA, 2008; e BRUNO, 2013) e como esta prática está constituindo a identidade (WOODWARD, 2002; e HALL, 2006) desses jovens. Através da análise desta pesquisa chegou-se não a conclusões, mas a questionamentos e reflexões sobre o trabalho que está sendo desenvolvido dentro das escolas, em especial à referida escola, e como este trabalho está contribuindo para a constituição da identidade destes jovens e adolescentes.
\end{abstract}

Palavras-Chave: escola; identidade; imaginário; narrativas; selfie.

\section{Resumen}

La popularización de las tecnologías digitales alteró el modo de cómo las relaciones sociales se establecen en la contemporaneidad. El acto de fotografiar ganó nuevos significados. A partir de esta perspectiva, el presente artículo tiene como objetivos analizar las narrativas construidas por jóvenes estudiantes a partir de las selfies, además de comprender los significados construidos por ellos en torno a esas imágenes. Las técnicas de investigación utilizadas fueron las entrevistas de grupo focal y entrevistas individuales con la profesora y con los estudiantes del Servicio Educativo Especializado de la Escuela Municipal de Enseñanza Fundamental Gonçalves Dias, ubicada en la ciudad de Portão (RS). El interés por la investigación surgió a partir de un proyecto presentado por los estudiantes en la FEICIP, Feria de Iniciación Científica de dicho municipio titulado: "Selfie

\footnotetext{
${ }^{1}$ Doutoranda em Processos e Manifestações Culturais; Universidade Feevale; Novo Hamburgo; Rio Grande do Sul; Brasil; dai.fontes@ hotmail.com

${ }^{2}$ Doutoranda em Processos Manifestações Culturais; Universidade Feevale; Novo Hamburgo; Rio Grande do Sul; Brasil; torres.jaqueline@yahoo.com.br

${ }^{3}$ Mestra em Processos e Manifestações Culturais; Universidade Feevale; Novo Hamburgo; Rio Grande do Sul; Brasil; sandracolling@gmail.com
} 
no es sólo disfrutar: un estudio en la E.M.E.F. "Gonçalves Dias". En el caso de la construcción de narrativas (RICOEUR, 2012) a partir del imaginario (PESAVENTO, 1995) producido por las selfies (SIBILIA, 2008, y BRUNO, 2013) y cómo esta práctica está constituyendo la identidad (WOODWARD, 2002, y HALL, 2006) de estos jóvenes. A través del análisis de esta investigación se llegó no a conclusiones, sino a cuestionamientos y reflexiones sobre el trabajo que se está desarrollando dentro de las escuelas, en especial a dicha escuela, y cómo este trabajo está contribuyendo a la constitución de la identidad de estos jóvenes y adolescentes.

Palabras clave: escuela; identidad; imaginário; narrativas; selfie.

\begin{abstract}
The popularization of digital technologies has altered the way in which social relations are established in contemporaneity. The act of photographing itself gained new meanings. From this perspective, this article aims to analyze the narratives constructed by young students from the selfies, in addition to understanding the meanings built by them around these images. The research techniques used were the focus group interviews and individual interviews with the teacher and the students of the Specialized Educational Attendance of the Gonçalves Dias Elementary School, located in the city of Portão (RS). The interest in the research came from a project presented by the students at FEICIP, the Scientific Initiation Fair of the mentioned municipality entitled: "Selfie is not just to enjoy: a study in E.M.E.F. Gonçalves Dias ". As a theoretical basis, we used the concepts of narrative construction (RICOEUR, 2012) from the imaginary (PESAVENTO, 1995) produced by selfies (SIBILIA, 2008 and BRUNO, 2013) and how this practice is constituting identity (WOODWARD, 2002, and HALL, 2006). Through the analysis of this research, we arrived not at conclusions, but at questions and reflections about the work being done within schools, especially at the school, and how this work is contributing to the identity of these young people and adolescents.
\end{abstract}

Keywords: identity; imaginary; narratives; school; selfie.

\title{
1. Introdução
}

Em agosto de 2018 ocorreu a V FEICIP, Feira de Iniciação Científica do município de Portão/RS (Figura 1). Portão é um município pertencente à região metropolitana de Porto Alegre, tem em torno de 30.000 habitantes e conta com 21 escolas de educação infantil e ensino fundamental da rede pública municipal, 04 escolas de ensino fundamental estaduais, 01 escola técnica estadual, 01 de atendimento especializado, 01 escola de ensino fundamental e médio da rede privada de ensino, 06 escolas particulares de educação infantil e uma faculdade privada. Feiras de iniciação científica sempre ocorreram nesse município, mas no formato atual é a $5^{\mathrm{a}}$ edição. 


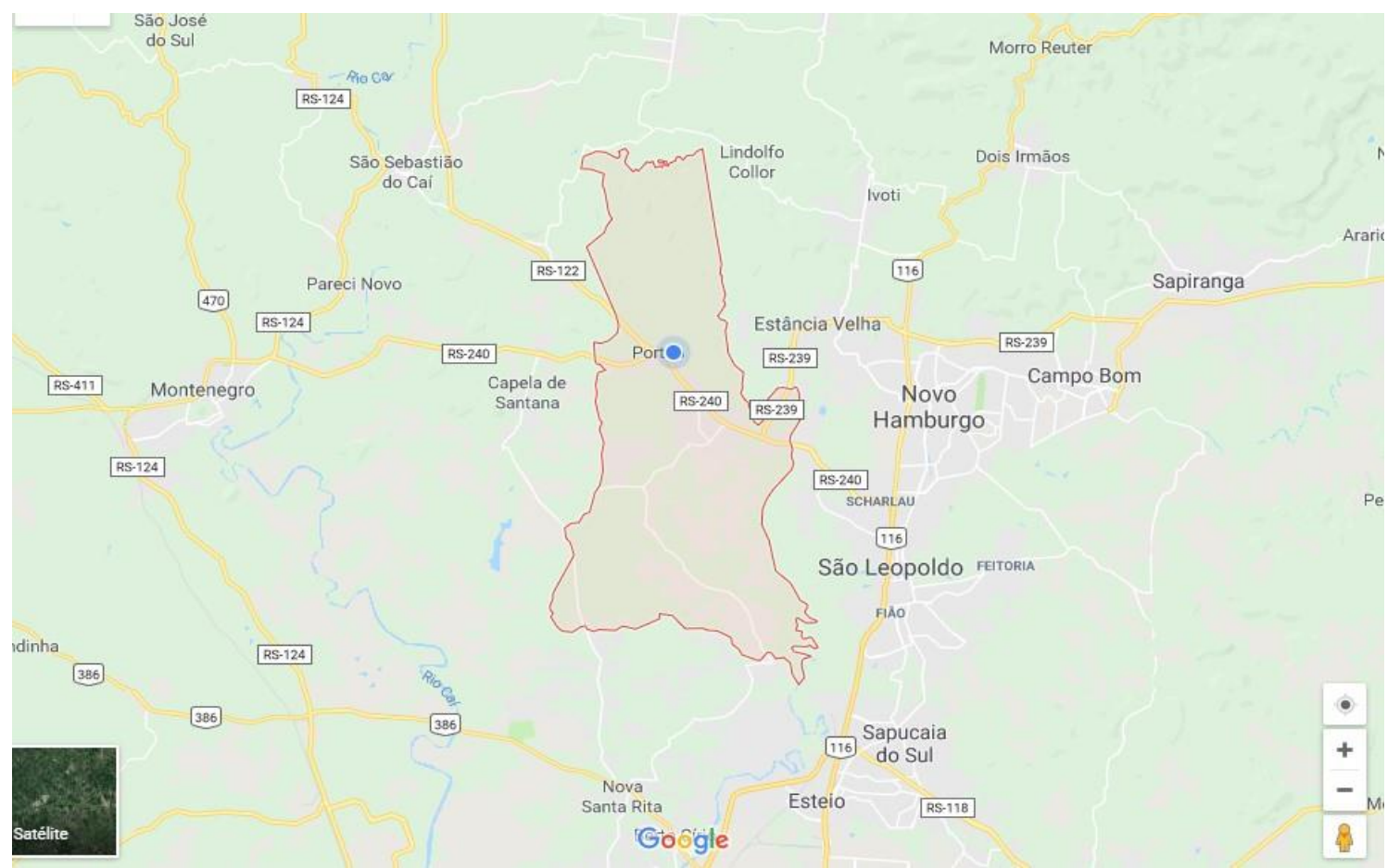

Figura 1 - Mapa de localização do município de Portão/RS Fonte: Google Maps, outubro de 2018.

Nesta Feira, alunos e professores da educação infantil e do ensino fundamental apresentam suas pesquisas sobre os mais diferentes temas. Um dos trabalhos apresentados intitulado "Selfie não é só curtir: um estudo na E.M.E.F. Gonçalves Dias", chamou a atenção pelo fato de estar propondo uma reflexão sobre o uso da selfie por adolescentes, de que modo isso ocorre com os jovens desse espaço escolar, como reagem a respeito da observação da própria imagem e a perspectiva de uma pesquisa mais avançada para se identificar os efeitos das ações realizadas pela escola e que possibilitam uma maior autoestima.

A Escola Municipal de Ensino Fundamental Gonçalves Dias (Figura 2) está situada na zona rural do município de Portão/RS, ao norte, na localidade de Cachoeira, tendo atualmente 194 alunos, 15 professores (entre eles uma de AEE - Atendimento Educacional Especializado $^{4}$ ), 03 funcionários para serviços gerais, diretor, secretária, supervisora e orientadora educacional. Essa escola atende alunos de lugares distantes dentro desse perímetro rural, sendo muitos deles oriundos do quilombo próximo à área escolar.

\footnotetext{
${ }^{4}$ Sala de aula que conta com profissional especializado para atendimento, no contraturno, de alunos com necessidades especiais.
} 


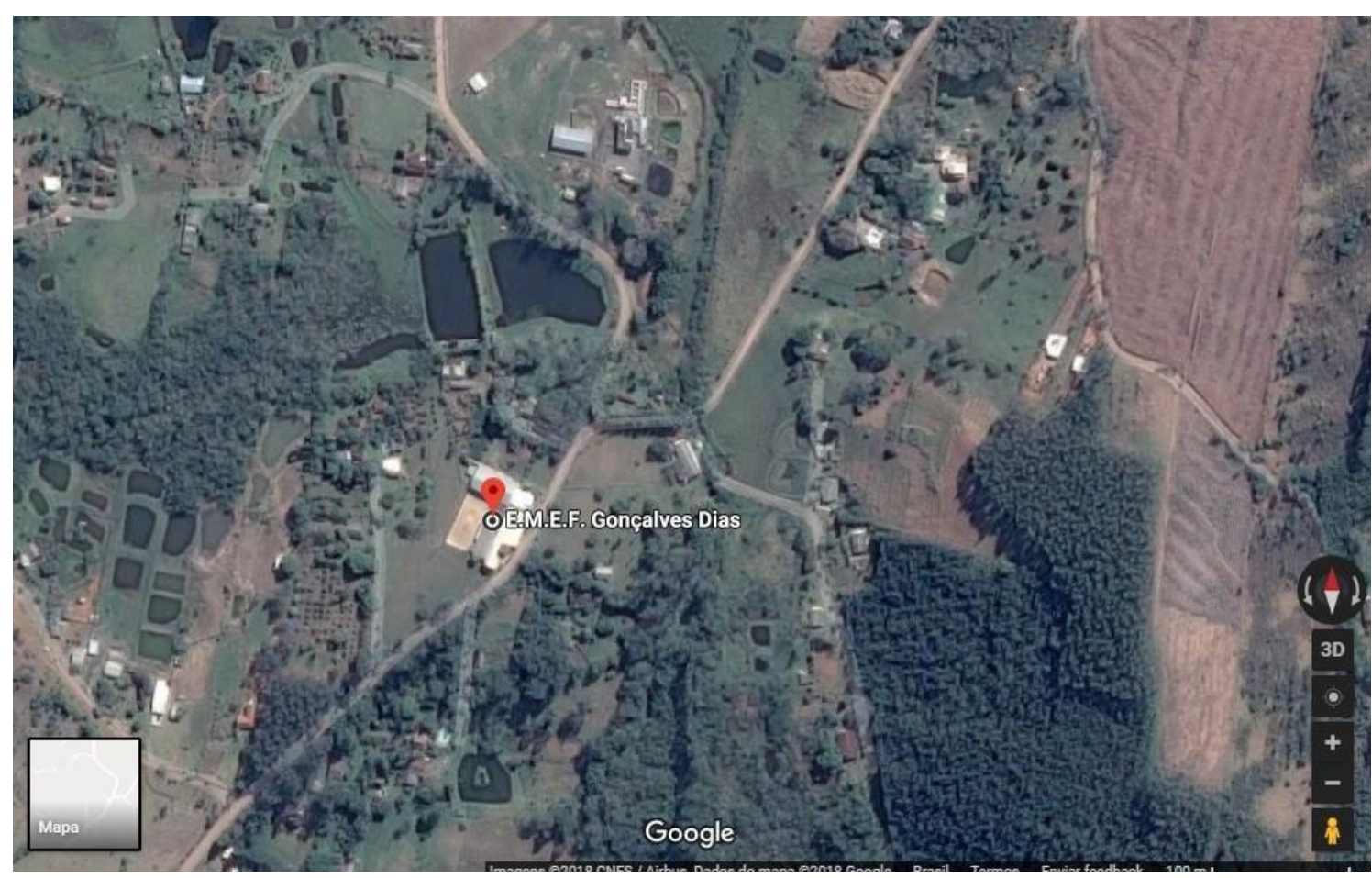

Figura 2 - Imagem aérea aproximada da EMEF Gonçalves Dias

Fonte: Google Maps, outubro de 2018.

Para esse trabalho, as técnicas de pesquisa utilizadas foram as entrevistas de grupo focal e entrevistas individuais com a professora e com os estudantes do Atendimento Educacional Especializado desta Escola. Essas entrevistas foram realizadas na própria escola, com as devidas autorizações, e trouxeram elementos para analisar as narrativas construídas por jovens estudantes a partir das selfies, além de compreender os significados construídos por eles em torno dessas imagens.

\section{Jovens e adolescentes: um olhar através das selfies}

Paul Ricoeur (2012), em seu ensaio Entre o Tempo e Narrativa: concordância/discordância, faz uma análise sobre narração baseando-se em três pressuposições.

$\mathrm{Na}$ primeira pressuposição, Ricoeur (2012) considera que "a despeito da heterogeneidade aparente das obras que são ordinariamente tratadas sob o título amplo de "narrativa" é sempre possível discernir a identidade do ato de narrar" (p. 299). E considera o conceito de intriga, ou melhor, pôr-em-intriga, como o "princípio estruturante subjacente às relações de família que permanecem, dizemos, entre narrativa de ficção e narrativa histórica como também, nas obras de ficção, entre epopeia, drama e romance" (p. 299). 
Esta primeira pressuposição, segundo o autor, não tem a ver com a hermenêutica da narração, uma vez que remonta uma pura análise estrutural. Entretanto, constitui o pano de fundo para a segunda pressuposição (RICOEUR, 2012). Sobre a segunda pressuposição, então, Ricoeur (2012) considera que:

É tarefa de uma hermenêutica desimplicar das pretensões referenciais de toda obra literária o tipo de mundo que essa obra desdobra. Podemos chamar tal mundo de "mundo da obra". O que é, com efeito, interpretado em um texto é um mundo próposto (pro-posé), um mundo que eu poderia habitar e no qual eu poderia projetar minhas capacidades mais próprias (RICOUER, 2012, p. 300).

Neste sentido, o "mundo da obra" pode ser interpretado por diversas pessoas e das mais variadas formas, uma vez que as interpretações são subjetivas e dependem do fator tempo, a terceira pressuposição de Ricoeur (2012):

A terceira pressuposição repousa sobre a precedente: considero que o caráter temporal da experiência humana é o que está em jogo especificamente nas pretensões referenciais de toda obra narrativa [...]. Em outros termos, o tempo devém tempo humano na medida em que é articulado de modo narrativo, e os relatos adquirem sentido ao tornarem-se as condições da existência temporal.

A defesa dessa terceira pressuposição implica em fazer a defesa das duas precedentes à medida que a identidade presumida no ato de narrar repousa sobre a capacidade do relato de projetar um mundo narrativo, e também à medida que essa capacidade é fundada por sua vez sobre a correlação primordial entre narratividade e temporalidade (RICOUER, 2012, p. 300).

Assim, as narrativas construídas pelos adolescentes da classe de Atendimento Educacional Especializado da Escola Municipal de Ensino Fundamental Gonçalves Dias só fizeram sentido para eles a partir do momento em que puderam contar as suas histórias, isto é, as suas interpretações de um presente das coisas passadas, num presente de coisas presentes, projetando um presente de coisas futuras (RICOEUR, 2012).

O trabalho de campo, então, foi realizado na sala de Atendimento Educacional Especializado, sendo uma grata surpresa saber que esta pesquisa foi desenvolvida por estes alunos. A professora Renata Scherer falou sobre o início do trabalho desenvolvido:

Dentro do atendimento educacional especializado eles têm todo um projeto de trabalho para desenvolver uma série de competências que entendemos que são importantes. E eles vieram com a ideia de que queriam participar da feira de ciências do município e eu disse então vamos participar. E aí dentro do projeto eu fui buscando desenvolver as competências dos planos, a parte de matemática, a parte de português, a gente começou tudo com a ideia do autorretrato do Mário Quintana, para ideia de selfie porque autorretrato agora se escreve tudo junto, a questão ortográfica, eles iam fazendo a pesquisa deles a partir dos interesses deles e eu puxando os conteúdos que eu entendia que eram importantes dentro da pesquisa. Mas a pesquisa em si, a ideia de selfie, tudo foi organizado e montado por eles. Eles são os protagonistas deste projeto. 
Após isso, os alunos se apresentaram e contaram algumas curiosidades como local e com quem moram, como se deslocam para a escola, sendo que dos três alunos que trabalharam nesta pesquisa, dois são oriundos da região do quilombo, em Macaco Branco, no município de Portão/RS. Como possuem algumas necessidades especiais, estão com diferença na idade em relação ao ano escolar que frequentam. Eles falam sobre alguns detalhes desde o início do projeto até às conclusões. Dariani, uma das alunas, afirma que:

Um dia a gente estava tendo aula e aí a professora pediu para a gente ler um texto que falava sobre fotografia, do Mário Quintana, daí a gente leu esse poema, daí depois a gente ficou pensando e daqui a pouco a gente pensou em fazer um projeto. Porque quando a gente tava lendo e pensando, veio essa ideia e a gente achou diferente e a gente queria fazer diferente. Porque normalmente nas feiras eles trabalham sempre com as mesmas coisas. E a gente pensou em ter uma ideia nova com um projeto novo.

Então, a conversa com observação participante vai para o modo como eles pensaram em coletar os dados para a pesquisa deles. Elen, outra aluna, logo disse "A gente fez um folheto com perguntas para os alunos do turno da manhã porque de tarde já estamos ocupados aqui". João, o terceiro aluno, disse: "Fizemos um questionário, explicamos e recolhemos no mesmo dia".

Eles contam que, após terem recolhido esse material, levaram para a sala, contaram, tabularam e montaram gráficos no computador. Dariani logo aponta a necessidade da busca de outras informações: “A gente pensou que deveria pesquisar mais sobre isso. Então a gente pesquisou os textos sobre a história da selfie e fomos trabalhando com esses textos, a gente estudou sobre o assunto das selfies". João disse que: "Pensando nos resultados dos gráfícos, a gente olhou os números e pensamos que na nossa escola uns não gostavam de tirar selfie e outros gostavam de tirar selfie, mas não postavam, não gostavam de mostrar para os outros".

A prática do autorretrato (selfies) adquiriu novos contornos com as redes sociais. A dinâmica da visibilidade e da publicização provocou afetações e deslocamentos de sentidos quanto ao ato de fotografar-se. A preocupação para os sujeitos das selfies consiste em tornar público, com a melhor iluminação, o melhor ângulo e o melhor cenário, aspectos de sua vida privada, tendo em vista que esses sujeitos na contemporaneidade são mediados por imagens e num "esquema no qual ser confunde-se com ser visto" (GALINDO, 2018, p. 50).

As selfies são espaços de legitimidade do eu. E para que tal legitimidade seja referendada por seus pares, faz-se necessário que as imagens sejam bonitas, de pessoas felizes e bem sucedidas. Para se enquadrar nos padrões desejados pelos sujeitos, essas imagens são “aperfeiçoadas, melhorada e corrigida", como aponta Manuela Arruda Galindo (2018, p. 53). 
Para a referida autora, é essa manipulação da fotografia digital que proporcionará a apreciação de forma positiva dessas imagens.

A visibilidade nessa dinâmica das redes sociais é percebida como um capital social relevante. O regime de visibilidade descrito por Fernanda Bruno (2013, p. 46) aponta que a exposição exagerada do eu no mundo contemporâneo "são vetores de prazeres, entretenimento e sociabilidade". Assim, "ver e ser visto ganham aqui sentidos atrelados à reputação, pertencimento, admiração, desejo, conferindo à visibilidade uma conotação prioritariamente positiva" (BRUNO, 2013, p. 47). Para a autora, cada período é formado por um regime de visibilidade próprio que estão constantemente sendo construído social e historicamente.

Paula Sibilia (2008) aponta que nos últimos anos houve uma grande necessidade das pessoas em conhecer a vida do "outro". A autora relata que o foco de visibilidade atualmente não concentra-se apenas nas pessoas famosas e/ou ditas celebridades. As atenções hoje são voltadas também para pessoas comuns. E uma das preocupações da autora é quanto ao limite entre o espaço público x espaço privado tendo em vista que: "vão se alargando os limites do que se pode dizer e mostrar, a esfera da intimidade se exacerba sob a luz de uma visibilidade que se deseja total.” (SIBILIA, 2008, p. 34).

Diante das novas transformações sociais e tecnológicas, Sibilia (2008, p. 34) questiona o significado do que seria "espaço privado" nesse novo contexto. Para a autora, são desfeitas "as fronteiras que separavam ambos os espaços que transcorria a existência, desafiando as velhas categorias e demandando novas interpretações”.

O século XXI produziu novos contornos em relação às narrativas. Cenas cotidianas são ordenadas para serem espetacularizadas e assim, os gestos habituais "mais insignificantes revelam certo parentesco com as cenas dos vídeos clipes e das publicidades”. (SIBILIA, 2008, 49). Não é à toa que ao postarem suas selfies os jovens e adolescentes queiram que suas publicações fiquem o mais próximo possível das que são publicadas pelos artistas, como aponta a fala de João no parágrafo a seguir.

Ao conversamos, então, sobre os resultados obtidos na pesquisa os alunos da classe de AEE da Escola Municipal de Ensino Fundamental Gonçalves Dias trouxeram as seguintes conclusões: a maioria dos alunos não posta sua selfie nas redes sociais por motivo de terem sofrido algum tipo de bullying. "Eu tô sempre dizendo que na televisão tem os artistas e as pessoas se comparam com os artistas que são bonitos, são jovens e tal, e aí acabam dizendo que não gostam de sua aparência”, aponta João. Para Dariani "os alunos sofrem bullying na escola e também na própria casa". 
Neste contexto, podemos aqui falar do imaginário, das representações construídas que estariam expressando uma "realidade". Sandra Pesavento (1995) entende que para se falar em imaginário, devemos começar abordando a noção de representação, uma vez que o “imaginário faz parte de um campo de representação e, como expressão do pensamento, se manifesta por imagens e discursos que pretendem dar uma definição da realidade" (PESAVENTO, 1995, p. 15).

Entretanto, segundo a autora, estas imagens e discursos sobre o real não são expressões literais da realidade. Existe uma diferença entre a concretude das condições objetivas e a representação que dela se faz:

Como afirma Bourdieu, as representações mentais envolvem atos de apreciação, conhecimento e reconhecimento e constituem um campo onde os agentes sociais investem seus interesses e sua bagagem cultural. As representações objetais, expressas em coisas ou atos, são produto de estratégias de interesse e manipulação. Ou seja, no domínio da representação, as coisas ditas, pensadas e expressas têm um outro sentido além daquele manifesto. Enquanto representação do real, o imaginário é sempre referência a um "outro" ausente. O imaginário enuncia, se reporta e evoca outra coisa não explícita e não presente (PESAVENTO, 1995, p. 15).

É construída, assim, uma dimensão simbólica da realidade onde se estabelece uma relação entre significantes (imagens, palavras) e significados (representações, significações). Desta forma, Pesavento (1995) ressalta que:

A rigor, todas as sociedades, ao longo de sua história, produziram suas próprias representações globais: trata-se da elaboração de um sistema de ideias-imagens de representação coletiva mediante o qual elas se atribuem uma identidade, estabelecem suas divisões, legitimam seu poder e concebem modelos para a conduta de seus membros. Seriam, pois, representações coletivas da realidade, e não reflexos da mesma. Há, assim, uma temporalidade da história nas representações (PESAVENTO, 1995, p. 16).

Assim, a autora entende que não existe, na elaboração das ideias-imagens de representação coletiva uma "verdade social", tão pouco uma relação de oposição entre a realidade ou o real como concreto e o pensado como "não-real" ou "não-verdadeiro". Há, desta forma, uma maneira de compreensão da realidade não só como "o que aconteceu", mas também como "o que foi pensado" ou mesmo "o que se desejou que acontecesse" (PESAVENTO, 1995, p. 16-17).

Pesavento (1995) atenta para o que os autores Robert Darton (1980) e Roger Chartier (1991) compreendem sobre os papeis que o discurso e a imagem podem desempenhar. Estes autores entendem que o discurso e a imagem "podem vir a ser instrumentos de constituição de poder e transformação da realidade" (p. 18). Assim, conclui Pesavento (1995, p. 18), nas palavras de Chartier, a "representação do real, ou o imaginário, é, em si, elemento de 
transformação do real e de atribuição de sentido ao mundo". Esta autora ainda traz o pensamento de outro autor, Pierre Bourdieu (1982):

Para Bourdieu, o mundo social é também representação e vontade, e todo discurso contém, em si, estratégias de interesses determinados. A autoridade de um discurso e a sua eficácia em termos de dominação simbólica vêm de fora: a palavra concentra o capital simbólico acumulado pelo grupo que o enuncia e pretende agir sobre o real, agindo sobre a representação deste real (PESAVENTO, 1995, p. 18).

Sandra Pesavento (1995, p. 19) refere-se também aos estudos de Chartier (1991) ao indicar o "caminho para decifrar a construção de um sentido num processo determinado: o cruzamento entre práticas sociais e historicamente diferenciadas com as representações feitas". A autora ressalta ainda que:

[...] as clivagens culturais não se organizam só através do recorte social, ocorrendo também configurações derivadas dos fatores sexo, idade, religião, tradição, educação, etc. As representações coletivas são ao mesmo tempo matriz e efeito das práticas construtoras do mundo social. Deixa de ter sentido, como já se acentuou, a discussão sobre a primazia desta ou daquela instância da realidade, por entendê-la múltipla, dinâmica, não determinada, relativa.

[...] A concepção do imaginário como função criadora se constrói pela via simbólica, que expressa a vontade de reconstruir o real num universo paralelo de sinais. (...) $\mathrm{O}$ símbolo se expressa por uma imagem, que é seu componente espacial, e por um sentido, que se reporta a um significado para além da representação explícita ou sensível. Em suma, através da imaginação simbólica, diz-se ou se mostra uma coisa ou uma ideia através de outra (PESAVENTO, 1995, p. 19-21).

Pesavento (1995) observa ainda que as ideias-imagens precisam de um apoio na concreticidade das condições reais de existência. Elas precisam, para serem aceitas socialmente, de um mínimo de verossimilhança com o mundo vivido. E as ideias-imagens utópicas garantem um suporte na hora de ordenar os sonhos e desejos coletivos.

É importante atentar para o poder da manipulação, que joga com esses sonhos e desejos coletivos, forjando mitos, crenças e símbolos, intervindo no processo de formação do imaginário coletivo. "Não se pode esquecer que o imaginário social é uma das forças reguladoras da vida coletiva, normatizando condutas e pautando perfis adequados ao sistema" (PESAVENTO, 1995, p. 23). Então,

O imaginário é, pois, representação, evocação, simulação, sentido e significado, jogo de espelhos onde o "verdadeiro" e o aparente se mesclam, estranha composição onde a metade visível evoca qualquer coisa de ausente e difícil de perceber. Persegui-lo como objeto de estudo é desvendar um segredo, é buscar um significado oculto, encontrar a chave para desfazer a representação do ser e parecer (PESAVENTO, 1995, p. 24) 
Sobre o racismo, os alunos da classe de AEE da Escola Municipal de Ensino Fundamental Gonçalves Dias afirmam que não acontece nenhum tipo de bullying que envolva o assunto. João disse que "aqui todo mundo se respeita". A professor Renata Scherer salienta que:

Aqui dentro da escola tem todo um trabalho de fortalecimento da identidade do quilombo, desta questão toda em relação aos trabalhos que vêm sendo desenvolvidos dentro da escola e acho que tem um trabalho de fortalecimento da identidade do negro muito bacana. Mas não podemos descartar esta hipótese também.

Passamos, assim, para a atividade realizada individualmente, que consistiu em solicitar que cada aluno fizesse, com o celular, uma ou mais selfies, para que depois respondessem algumas questões previstas em nosso roteiro. As questões eram: O que mais gosta nessa imagem? O que não gosta nessa imagem? O que teria que mudar nesta imagem? Você postaria nas redes sociais essa imagem? Por quê? Cada aluno respondeu as perguntas olhando para a sua imagem no celular.

As respostas dos jovens trouxeram aspectos positivos e negativos observados em si mesmos, com desejos de alteração em alguns aspectos e, de forma geral, nenhum dos alunos colocaria sua selfie nas redes sociais. Os motivos foram variados, sendo os principais: "eu não gosto dessa imagem"; "não quero que os outros vejam essa imagem" e "eu não gosto de fazer selfie porque todas as pessoas olham e têm algumas pessoas que ficam pegando no meu pé, porque eles ficam me chamando de orelhudo. Também já me chamaram de cabeçudo”.

É possível perceber no parágrafo acima que a prática das selfies está constituindo novas formas identitárias para esses jovens. Para Kathryn Woodward (2002) a identidade só adquire sentido através da linguagem e do sistema simbólico e social e são construídas em momentos particulares no tempo. Neste caso, se um grupo é marcado simbolicamente pela prática da selfie, por exemplo, pode-se inferir que o grupo que não pertencer a essas novas formas de relacionamento com o ato fotográfico não pertencerá àquele grupo social. As mudanças no campo da identidade devido às transformações globais e as mudanças nos padrões de produção e de consumo estão produzindo novas identidades. Tais mudanças têm provocado o que Woodward (2002) e Stuart Hall (2006) apontam como uma "crise de identidade" que seriam provenientes das transformações da vida contemporânea.

Hall (2006, p. 7) aponta que a "crise de identidade" é percebida "como parte de um processo mais amplo de mudança, que está deslocando as estruturas e processos centrais das sociedades modernas e abalando os quadros de referências que davam aos indivíduos uma ancoragem estável no mundo social". Uma dessas mudanças é ocasionada pelo que o autor 
denominou de sujeito pós-moderno. O referido sujeito possui uma identidade fragmentada, mutável e contraditória e, dessa maneira:

O sujeito assume identidades diferentes em diferentes momentos, identidades que não são unificadas ao redor de um 'eu' coerente. Dentro de nós há identidades contraditórias, empurrando em diferentes direções, de tal modo que nossas identificações estão sendo continuamente deslocadas. Se sentimos que temos uma identidade unificada desde o nascimento até a morte é apenas porque construímos uma cômoda estória sobre nós mesmos ou uma confortadora 'narrativa do eu' (HALL, 2006, p. 6 - grifo do autor).

As posições identitárias que assumimos e com as quais nos identificamos constitui uma identidade e relaciona-se fortemente com subjetividade, pois envolve os "pensamentos e as emoções conscientes e inconscientes que constituem nossas concepções sobre 'quem nós somos'. A subjetividade envolve nossos sentimentos e pensamentos mais pessoais" (WOODWARD, 2002, p. 55-56). Sendo a rede social um espaço de trocas, de relacionamentos, de interações e de afirmações podemos dizer que os sujeitos vivem suas subjetividades nessa ambiência. Cada pessoa apresenta-se da maneira como gostaria de ser visto pelo outro e assim suas identidades vão sendo (re) construídas.

Assim, se percebe a importância que o outro produz em nosso imaginário. Isso está presente na narrativa sobre a imagem dos artistas e também no poder que é dado ao que os outros possam pensar ao ver minha imagem, no caso dos adolescentes.

\section{Conclusões}

De acordo com a pesquisa realizada pelos alunos da Escola Municipal de Ensino Fundamental Gonçalves Dias, após terem aplicado 98 questionários entre jovens do $6^{\circ}$ ao $9^{\circ}$ ano da referida escola, os resultados foram os seguintes: $70 \%$ dos alunos gostam de tirar selfie, mas desses $70 \%$, apenas $35 \%$ publica nas redes sociais porque gosta de sua imagem. Com esse estudo foi possível concluir que muitos alunos da escola não têm uma boa relação com a sua autoimagem e os pesquisadores acreditam que uma justificativa para essa situação, entre outras não descartadas, possa ser encontrada nas mídias, onde a beleza é cultuada, e no aumento do bullying entre adolescentes. Como são muitas as hipóteses apresentadas por eles ao final da pesquisa realizada na escola, é importante que possam continuar investigando e promovendo debates sobre o assunto para que compreendam o que está fazendo com que os alunos não gostem de postar as selfies que fazem com seus celulares nas redes sociais.

Podemos então, ao final deste artigo, levantar os seguintes questionamentos: Será que o trabalho de empoderamento realizado na escola está permitindo que a questão do racismo 
não aconteça neste ambiente e que não afete estes alunos, que são, em sua maioria, descendentes de quilombolas? O bullying entre os jovens, presente segundo os relatos dos alunos, seria a principal motivação deste não gostar da própria imagem? Em que medida estes alunos, que frequentam a sala de atendimento educacional especializado, que em nossa pesquisa ação, apresentaram 100\% de rejeição à própria imagem, também são afetados pelo bullying e, até mesmo, racismo? Esse artigo não traz respostas, mas levanta possibilidades e um alerta para que se tenha um olhar atento para com nossos alunos.

Com as constantes mudanças devido às transformações sociais, tecnológicas e culturais, é de fundamental importância que novas práticas de ensino-aprendizagem sejam incorporadas ao currículo dos jovens estudantes. O trabalho que está sendo desenvolvido com os estudantes do Atendimento Educacional Especializado da Escola Municipal de Ensino Fundamental Gonçalves Dias é uma relevante possibilidade de estímulo ao pensamento crítico propondo problematizações inerentes ao universo dos pesquisados e com isso contribuindo para a constituição da identidade destes jovens e adolescentes.

\section{Referências}

BRUNO, Fernanda. Máquinas de ver, modos de ser: vigilância, tecnologia e subjetividade. Porto Alegre: Sulina, 2013.

GALINDO, Manuela Arruda. Selfies e subjetividade contemporânea. In: MONTARDO, Sandra (org.). Selfies: subjetividade e tecnologia. - Porto Alegre: Sulina, 2018 (p. 47 - 70 )

HALL, Stuart. A identidade cultural na pós-modernidade. 11. ed. Rio de Janeiro: DP\&A, 2006.

MONTARDO, Sandra (org.). Selfies: subjetividade e tecnologia. - Porto Alegre: Sulina, 2018.

PESAVENTO, Sandra J. Em busca de outra história: Imaginando o imaginário. Revista Brasileira de História, v.15, n.29, 1995.

RICOEUR, Paul. Entre Tempo e Narrativa: Concordância/Discordância. Tradução: João Batista Botton. Kriterion, Belo Horizonte, $\mathrm{n}^{\circ}$ 125, Jun./2012, p. 299-310

SIBILIA, Paula. O show do eu: a intimidade como espetáculo. Rio de Janeiro, Nova Fronteira, 2008.

WOODWARD, Kathryn. Identidade e diferença: uma introdução teórica e conceitual, in: SILVA, Tomaz Tadeu (org.), Identidade e diferença: a perspectiva dos estudos culturais. 12. ed. Petrópolis, Vozes, 2002.

Vista de mapa de Portão/RS. Acesso em 27/10/2018. Disponível em: https://www.google.com/maps/place/Port\%C3\%A3o+-+RS/@-29.6924672,- 
RELACult - Revista Latino-Americana de Estudos em Cultura e Sociedade

Revista Latinoamericana de Estudios en Cultura y Sociedad | Latin American Journal of Studies in Culture and Society V. 05, ed. especial, abr., 2019, artigo no 1130 | claec.org/relacult | e-ISSN: 2525-7870

$51.386109,11 \mathrm{z} / \mathrm{data}=! 3 \mathrm{~m} 1$ !4b1!4m5!3m4!1s0x95195bf5755e3643:0x520f1e920ca93d $81 ! 8 \mathrm{~m} 2$ !3d-29.6932181!4d-51.2306098 